[19] Tagalakis, V., Patenaude, V., Kahn, S. R., Suissa, S. (2013). Incidence of and Mortality from Venous Thromboembolism in a Real-world Population: The Q-VTE Study Cohort. The American Journal of Medicine, 126 (9), 13-21. doi: http://doi.org/ 10.1016/j.amjmed.2013.02.024

[20] Sapelkin, S. V., Kuznetsov, M. R. (2016). Konservativnoye lecheniye bol'nykh s zabolevaniyami perifericheskikh arteriy: vozmozhnosti i sushchestvuyushchiye problemy. Angiologiya i sosudistaya khirurgiya, 4, 169-175.

[21] Ferreira, V., Freixo, C., Gonçalves, J., Teixeira, G., Antunes, I., Veiga, C. et. al. (2019). Effectiveness and Safety of Rivaroxaban Compared to Acenocumarol after Infrainguinal Surgical Revascularization. Annals of Vascular Surgery, 55, 78-84. doi: http:// doi.org/10.1016/j.avsg.2018.06.008

[22] Halle, T. R., Benarroch-Gampel, J., Teodorescu, V. J., Rajani, R. R. (2018). Surgical Intervention for Peripheral Artery Disease Does Not Improve Patient Compliance with Recommended Medical Therapy. Annals of Vascular Surgery, 46, $104-111$. doi: http://doi.org/10.1016/j.avsg.2017.06.152

[23] Bhagirath, V. C., Eikelboom, J. W., Anand, S. S. (2018). Low-dose rivaroxaban plus aspirin for the prevention of cardiovascular events: an evaluation of COMPASS. Future Cardiology, 14 (6), 443-453. doi: http://doi.org/10.2217/fca-2018-0059

\title{
MAGNETIC RESONANCE IMAGING WITH DIFFUSE WEIGHTED IMAGING AND COMPUTED TOMOGRAPHY WITH INTRAVENOUS CONTRAST IN STAGING OF DISSEMINATED OVARIAN, STOMACH, COLORECTAL CANCER
}

\author{
Sergiy Chetverikov \\ Surgery department No.4 with oncology course ${ }^{l}$ \\ chetverikov@rambler.ru \\ Svitlana Zavoloka \\ Surgery department No. 4 with oncology course \\ zavsvetlana.od@gmail.com \\ Viacheslav Onyshchenko \\ Department of simulation medicine \\ Odessa National Medical University \\ 2 Valichovskiy lane, Odessa, Ukraine, 65082 \\ vicedeanodessa@gmail.com \\ Mykhailo Chetverikov ${ }^{1}$ \\ chetvericov@yahoo.com \\ Valeriia Chetverikova-Ovchynnyk ${ }^{l}$ \\ ovchinnik.val@yahoo.com \\ ${ }^{1}$ Center of Reconstructive and Restorative Medicine \\ University Clinic of Odessa National Medical University \\ 8 Tenista str., Odessa, Ukraine, 65009
}

Abstract

The aim of the research. Development and implementation of new methods for pre-operative staging of advanced ovarian, gastric and colorectal cancer to improve patient selection for cytoreductive surgery and increase its radicality. 
Materials and methods. Data from 120 patients with advanced ovarian cancer, 28 with advanced gastric cancer and 119 with advanced colorectal cancer were analyzed. Preoperative detection of the incidence of peritoneal carcinoma and the possibility of surgery in radical or cytoreductive volume performed by $\mathrm{CT}$ with intravenous contrast (72 patients with ovarian cancer, 17 patients with gastric cancer, and 69 patients with colorectal cancer), and MR T1 and T2, contrast-enhanced T1, and diffuse-weighted sequences (48 patients with ovarian cancer, 11 patients with gastric cancer, and 50 patients with colorectal cancer). Subsequently, preoperative and intraoperative assessment of the prevalence of the tumour process with peritoneal carcinoma index (PCI) by Sugarbaker was performed.

Results. A statistically significant increase in the informativeness of the preoperative assessment of the incidence of tumour process in peritoneum and the presence of distant metastases using DWI/MRI compared with CT with intravenous contrast was determined. Patients from all groups were categorized according to the completeness index of cytoreduction achieved by preoperative staging and patient selection using DWI/MRI and CT. The use of DWI/MRI allowed to significantly reduce the number of suboptimal and non-optimal cytoreductive interventions.

Conclusions. DWI/MRI has made it possible to significantly improve the preoperative incidence of advanced ovarian, gastric, and colorectal cancer compared to CT, predict the radicality of future surgery, and detect inoperable cases.

Keywords: magnetic resonance imaging with diffuse-weighted imaging (DWI/MRI), computed tomography (CT), peritoneal carcinoma index (PCI), cytoreductive surgery.

DOI: $10.21303 / 2504-5679.2019 .001071$

\section{Introduction}

According to the National cancer registry of Ukraine, in 2017, with ovarian, gastric and colorectal stage III cancer patients were diagnosed $43.4 \%, 22.3 \%$, and $23.5 \%$ of patients, respectively; stage IV $-15.5 \%, 37.8 \%$ and $22.9 \%$ of patients, respectively. Surgical and chemotherapeutic treatment are the main methods of control of these diseases and the radicality of the surgery largely determines the degree of response to the chemotherapy treatment and the overall and relapse-free survival of patients $[1,2]$. At present, the main method of diagnosis of locally advanced processes in the abdomen is computed tomography with intravenous contrast (CT) [3]. Correct preoperative staging with the help of peritoneal index of carcinomatosis proposed by P. Shugarbaker allows to determine the order of combinated treatment, the expediency of surgical treatment and its probable volume and radicality $[4,5]$. However, according to the literature, CT does not allow to achieve a significant correlation in the estimation of the extent of abdominal tumour and the possibility of its complete removal. Magnetic resonance imaging using diffuse-weighted imaging (DWI/MRI) can be a complement or alternative to $\mathrm{CT}$ in these cases $[6,7]$.

The aim of the research - development and implementation of new methods of pre-operative staging of advanced ovarian, gastric and colorectal cancer to improve patient selection for cytoreductive surgery and increase its radicality.

\section{Materials and methods}

Clinical cases of 120 patients with advanced ovarian cancer (stage III and IV with final diagnosis), 28 with advanced gastric cancer (stage IV with final diagnosis) and 119 with advanced colorectal cancer (stage IV with final diagnosis) were considered. Preoperative detection of the incidence of peritoneal carcinoma and the possibility of surgery in radical or cytoreductive volume performed by CT with intravenous contrast ( 72 patients with ovarian cancer, 17 patients with gastric cancer, and 69 patients with colorectal cancer), and MR T1 and $\mathrm{T} 2$, contrast-enhanced T1, and diffuse-weighted sequences (48 patients with ovarian cancer, 11 patients with gastric cancer, and 50 patients with colorectal cancer). Subsequently, preoperative and intraoperative assessment of the incidence of tumour process by the peritoneal carcinomatosis index (PCI) by Sugarbaker was performed. Preoperative PCI restaging by both methods was performed by two radiologists independently including differences in statistical analysis to generate generalized values and compared with intraoperative evaluation. Patients were categorized by us according to the value of intraoperative PCI into three groups (PCI $<10$, $10<\mathrm{PCI}<20, \mathrm{PCI}>20$ ), due to the complexity of achieving optimal cytoreduction in these cases of the prevalence of tumour process and the index of completeness of cytoreduction, which illustrated radicality intervention $[8,9]$. 
The research was carried out within the framework of the scientific work of the Department of Surgery No. 4 with the oncology course of the Odessa National Medical University. Compliance with the WMA Declaration of Helsinki - Ethical Principles for Medical Research Involving Human Subjects, 2013 (minutes of the meeting of the Committee on Bioethics of the Odessa National Medical University No. 167A dated September 12, 2019) was determined. All study participants were informed and agreed to the processing of their clinical data and to participate in the research process.

Statistical analysis of the obtained data was performed using GNU PSPP version 1.2.0 using the non-parametric Friedmann $\chi^{2}$ test.

\section{Results}

In patients with ovarian cancer, DWI/MRI better revealed distant metastases in 8 out of 9 patients, compared to 2 in 15 with CT. In the category of patients with $\mathrm{PCI}<10$, similar to intraoperative staging with DWI / MRI was obtained in 22 of 23 patients (95.7\%), versus 15 of 43 (34.9\%) with CT $(\mathrm{p}<0.05)$. In the category of patients with $10<\mathrm{PCI}<20 \mathrm{DWI} / \mathrm{MRI}-13$ out of $15(86.7 \%)$, CT 5 out of $17(29.4 \%)(\mathrm{p}<0.05)$. In the category of patients with PCI $>20$ DWI / MRI -9 out of 10 $(90 \%)$, CT 3 out of $12(25 \%)(\mathrm{p}<0.05)$ (Fig. 1).

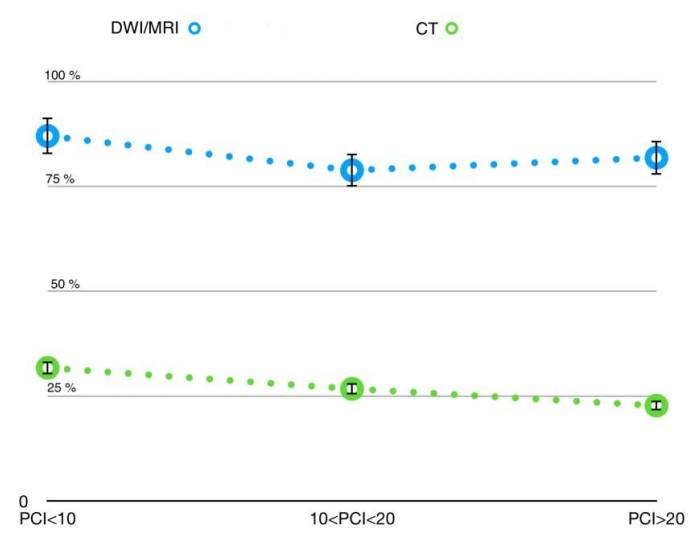

Fig. 1. The proportion of patients with similar preoperative and intraoperative staging with DWI/MRI and CT in ovarian cancer.

In patients with gastric cancer DWI/MRI, distant metastases were detected in 4 of 5 patients, compared with 6 of 11 in CT. In the category of patients with $\mathrm{PCI}<10$, similar staging using DWI/MRI was obtained in 3 of 3 patients $(100 \%)$, versus 2 of $5(40 \%)$ at $\mathrm{CT}(\mathrm{p}<0.05)$. In the category of patients with $10<\mathrm{PCI}<20$ DWI/MRI -3 out of $4(75 \%)$, CT 3 out of $7(42.8 \%)(\mathrm{p}<0.05)$. In the category of patients with PCI $>20$ DWI / MRI -4 out of $4(100 \%)$, CT 3 out of $5(60 \%)(p<0.05)$ (Fig. 2).

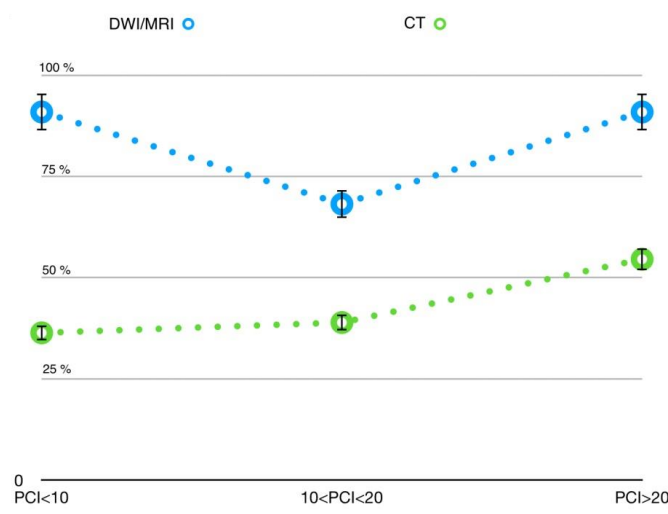

Fig 2. The proportion of patients with similar preoperative and intraoperative staging with DWI/MRI and CT in gastric cancer. 
In patients with colorectal cancer, DWI/MRI better revealed distant metastases in 7 out of 10 patients, compared with 3 in 10 with CT. In the category of patients with $\mathrm{PCI}<10$, similar staging using DWI/MRI was obtained in 15 of 17 patients $(88.2 \%)$, versus 12 of $21(57.1 \%)$ with CT $(\mathrm{p}<0.05)$. In the category of patients with $10<\mathrm{PCI}<20 \mathrm{DWI} / \mathrm{MRI}-18$ out of $20(90 \%)$, CT 10 out of $32(31.2 \%)(p<0.05)$. In the category of patients with PCI $>20$ DWI/MRI -11 out of $13(84.6 \%)$, CT 5 out of $16(31.2 \%)(p<0.05)$ (Fig. 3$)$.

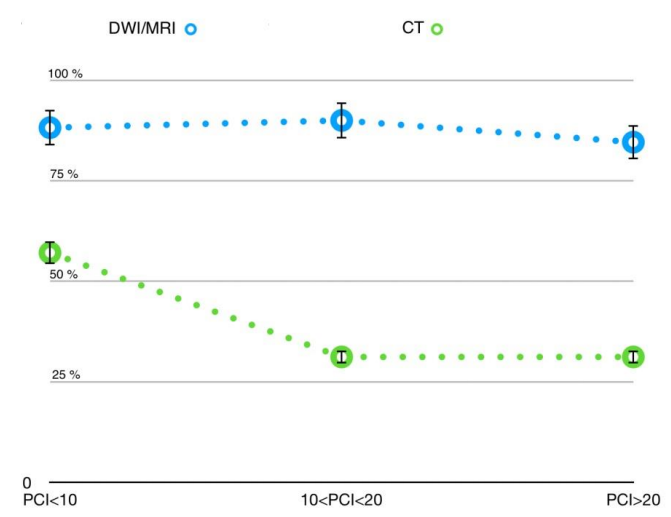

Fig. 3. The proportion of patients with similar preoperative and intraoperative staging with DWI/MRI and CT in colorectal cancer

Patients from all groups were categorized according to the completeness of cytoreduction index achieved through preoperative staging and patient selection using DWI/MRI and CT. Optimal CC-0 cytoreduction (no macroscopic residual tumor) and radical surgery were achieved in $53 \%$ of patients staged with DWI/MRI and $46 \%$ staged with CT $(\mathrm{p}<0.05)$. Suboptimal cytoreduction of CC-1 (residual tumor less than $2.5 \mathrm{~mm}$ ) were achieved in $37 \%$ of patients staged with DWI/MRI and $29 \%$ staged with CT $(\mathrm{p}<0.05)$. Non-optimal CC-2-3 cytoreduction (residual lesions greater than $2.5 \mathrm{~mm}$ ) were achieved in $10 \%$ of patients staged with DWI/MRI and $25 \%$ staged with CT $(\mathrm{p}<0.05)$ (Fig. 4).

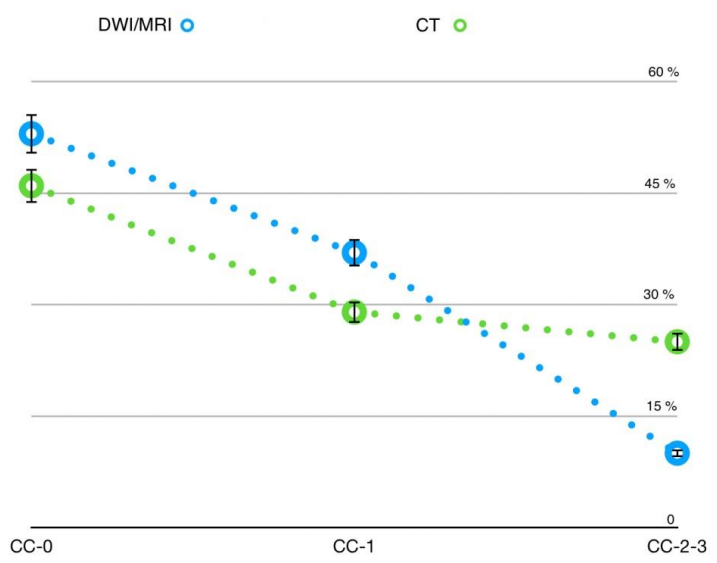

Fig. 4. The proportion of patients among whom optimal (CC-0), suboptimal (CC-1) and nonoptimal (CC-2-3) cytoreduction was achieved with preoperative staging using DWI/MRI and CT

\section{Discussion of the results}

Compared with other studies of the efficacy and relative efficacy of DWI/MRI in colorectal cancer [10, 11], ovarian cancer [12, 13] and stomach cancer [14, 15], similar results are obtained, illustrating the reproducibility of the experiment regardless of the treatment center used, study protocols, and subjective evaluation of PCI ranking results. 
The obtained results allow us to recommend DWI/MRI for pre-operative staging at all three investigated localizations of the tumour process. Comparing the results of staging with DWI/MRI revealed a significant number of advantages over CT. First, DWI/MRI revealed a greater number of distant metastases, which in the future will allow in these cases to correctly select the stage of complex cancer treatment in patients requiring neoadjuvant chemotherapy before primary cytoreductive surgery [16]. Second, DWI/MRI in many cases of ovarian cancer revealed lesions of visually and palpatory unchanged regional lymph nodes. This fact will, in the long run, reduce the number of routine lymph node dissections in visually unaffected lymph nodes without reducing the radicalism of surgery and worsening the oncological results in these patients [17]. A similar situation arises when addressing the issue of extending standard volumes of lymph node dissection in gastric and colorectal cancer $[18,19]$. Third, in the analysis of the local spread of the oncological process by the DWI/MRI method, the significant correlation of preoperative and intraoperative PCI allowed to predict better the future surgery, which made it possible to increase the radicality of the interventions. Also, CT sensitivity was limited by the size of tumors less than $5 \mathrm{~mm}$ and localization in certain anatomical areas (e. g. Omental foramen, lesser omentum, left hemidiaphragm and serous surface of the small intestine). However, a greater sensitivity of imaging with DWI/MRI was obtained in the presence of infiltrative and miliary carcinomatosis, which in many cases remained unnoticed in CT diagnosis, which dramatically changed the stage and volume of the operation. Better sensitivity of DWI/MRI, even at high PCI values, is also important, as it is in this group of patients that cases of inability to perform the optimal amount of cytoreductive intervention have been observed, which significantly impaired the predicted cancer outcomes. Despite these advantages, the relatively high cost, long study time, and the presence of absolute contraindications put the MRI on the second line for the detection and evaluation of tumors of the abdominal cavity.

Study limitations. This study was monocentric, nonrandomized and retrospective. The main limitation of the study is the retrospective recruitment of groups of patients who underwent surgery after pre-operative staging, and therefore did not include patients declared inoperable and patients with potentially suboptimal cytoreduction who were advised with neoadjuvant chemotherapy. The investigated data used the restaging of the pre-operative evaluation of the prevalence of the tumor process, conducted by two independent radiologists already at the time of the retrospective study, which in some cases differed from the conclusions obtained by patients during pre-operative diagnosis.

Prospects for further research. In the future, it is planned to compare the results obtained with the results of preoperative staging of widespread oncological processes by means of positron emission computed tomography and positron emission magnetic resonance imaging, which, like DWI/MRI, supplement information on molecular level disorders to the clear visualization of tissues and organs achieved by the main research [20].

\section{Conclusions}

DWI/MRI significantly improves the pre-operative staging of advanced ovarian, gastric and colorectal cancer compared to CT, predicts the radicality of future surgery and identifies inoperable cases. DWI/MRI significantly outperforms CT in visualization of metastatic lesions of the peritoneum, abdominal organs, and extraperitoneal space for ovarian, gastric, and colorectal cancer. DWI/MRI can be used in planning of the treatment of these diseases, reducing the number of unnecessary exploratory laparotomies and suboptimal cytoreductive interventions.

\section{Conflict of interest}

No conflict of interest.

\section{References}

[1] Hallam, S., Tyler, R., Price, M., Beggs, A., Youssef, H. (2019). Meta-analysis of prognostic factors for patients with colorectal peritoneal metastasis undergoing cytoreductive surgery and heated intraperitoneal chemotherapy. BJS Open, 3 (5), 585-594. doi: http://doi.org/10.1002/bjs5.50179 
[2] Wang, H. M., Wang, G. Y., Huang, Y., Ren, L., Zhang, H., Wu, A. W. et. al. (2019). The status analysis of diagnosis and treatment of synchronous peritoneal carcinomatosis from colorectal cancer in China: a report of 1003 cases in 16 domestic medical centers. Zhonghua Wai Ke Za Zhi, 57 (9), 666-672.

[3] Thomassin-Naggara, I., Darai, E., Lécuru, F., Fournier, L. (2019). Diagnostic value of imaging (ultrasonography, doppler, CT, MR, PET-CT) for the diagnosis of a suspicious ovarian mass and staging of ovarian, tubal or primary peritoneal cancer: Article drafted from the French Guidelines in oncology entitled «Initial management of patients with epithelial ovarian cancer» developed by FRANCOGYN, CNGOF, SFOG, GINECO-ARCAGY under the aegis of CNGOF and endorsed by INCa. Gynécologie Obstétrique Fertilité \& Sénologie, 47 (2), 123-133. doi: http://doi.org/10.1016/ j.gofs.2018.12.012

[4] Elzarkaa, A. A., Shaalan, W., Elemam, D., Mansour, H., Melis, M., Malik, E., Soliman, A. A. (2018). Peritoneal cancer index as a predictor of survival in advanced stage serous epithelial ovarian cancer: a prospective study. Journal of Gynecologic Oncology, 29 (4). doi: http://doi.org/10.3802/jgo.2018.29.e47

[5] Huang, Y., Alzahrani, N. A., Chua, T. C., Liauw, W., Morris, D. L. (2016). Impacts of peritoneal cancer index on the survival outcomes of patients with colorectal peritoneal carcinomatosis. International Journal of Surgery, 32, 65-70. doi: http:// doi.org/10.1016/j.ijsu.2016.06.033

[6] Van ’t Sant, I., van Eden, W. J., Engbersen, M. P., Kok, N. F. M., Woensdregt, K., Lambregts, D. M. J. et. al. (2018). Diffusion-weighted MRI assessment of the peritoneal cancer index before cytoreductive surgery. British Journal of Surgery, 106 (4), 491-498. doi: http://doi.org/10.1002/bjs.10989

[7] Cianci, R., Pizzi, A. D., Patriarca, G., Massari, R., Basilico, R., Gabrielli, D., Filippone, A. (20019). Magnetic Resonance Assessment of Peritoneal Carcinomatosis: Is There a True Benefit From Diffusion-Weighted Imaging? Current Problems in Diagnostic Radiology. doi: http://doi.org/10.1067/j.cpradiol.2019.06.002

[8] Llueca, A., Serra, A., Rivadulla, I., Gomez, L., Escrig, J. (2018). Prediction of suboptimal cytoreductive surgery in patients with advanced ovarian cancer based on preoperative and intraoperative determination of the peritoneal carcinomatosis index. World Journal of Surgical Oncology, 16 (1). doi: http://doi.org/10.1186/s12957-018-1339-0

[9] Coccolini, F., Catena, F., Glehen, O., Yonemura, Y., Sugarbaker, P. H., Piso, P. et. al. (2015). Complete versus incomplete cytoreduction in peritoneal carcinosis from gastric cancer, with consideration to PCI cut-off. Systematic review and meta-analysis. European Journal of Surgical Oncology (EJSO), 41 (7), 911-919. doi: http://doi.org/10.1016/j.ejso. 2015.03.231

[10] Dresen, R. C., De Vuysere, S., De Keyzer, F., Van Cutsem, E., Prenen, H., Vanslembrouck, R. et. al. (2019). Whole-body diffusion-weighted MRI for operability assessment in patients with colorectal cancer and peritoneal metastases. Cancer Imaging, 19 (1). doi: http://doi.org/10.1186/s40644-018-0187-z

[11] Barral, M., Eveno, C., Hoeffel, C., Boudiaf, M., Bazeries, P., Foucher, R. et. al. (2016). Diffusion-weighted magnetic resonance imaging in colorectal cancer. Journal of Visceral Surgery, 153 (5), 361-369. doi: http://doi.org/10.1016/j.jviscsurg. 2016.08.004

[12] Engbersen, M. P., van' t Sant, I., Lok, C., Lambregts, D. M. J., Sonke, G. S., Beets-Tan, R. G. H. et. al. (2019). MRI with diffusion-weighted imaging to predict feasibility of complete cytoreduction with the peritoneal cancer index (PCI) in advanced stage ovarian cancer patients. European Journal of Radiology, 114, 146-151. doi: http://oi.org/10.1016/ j.ejrad.2019.03.007

[13] Yuan, X., Guo, L., Du, W., Mo, F., Liu, M. (2017). Diagnostic accuracy of DWI in patients with ovarian cancer. Medicine, 96 (19), e6659. doi: http://doi.org/10.1097/md.0000000000006659

[14] Arslan, H., Fatih Özbay, M., Çallı, İ., Doğan, E., Çelik, S., Batur, A. et. al. (2017). Contribution of diffusion weighted MRI to diagnosis and staging in gastric tumors and comparison with multi-detector computed tomography. Radiology and Oncology, 51 (1), 23-29. doi: http://doi.org/10.1515/raon-2017-0002

[15] Liu, S., Wang, H., Guan, W., Pan, L., Zhou, Z., Yu, H. et. al. (2015). Preoperative apparent diffusion coefficient value of gastric cancer by diffusion-weighted imaging: Correlations with postoperative TNM staging. Journal of Magnetic Resonance Imaging, 42 (3), 837-843. doi: http://doi.org/10.1002/jmri.24841

[16] Coleridge, S. L., Bryant, A., Lyons, T. J., Goodall, R. J., Kehoe, S., Morrison, J. (2019). Chemotherapy versus surgery for initial treatment in advanced ovarian epithelial cancer. Cochrane Database of Systematic Reviews. doi: http://doi.org/10.1002/ 14651858.cd005343.pub4

[17] Salgado-Ceballos, I., Ríos, J., Pérez-Montiel, D., Gallardo, L., Barquet-Muñoz, S., Salcedo-Hernández, R. et. al. (2017). Is lymphadenectomy necessary in mucinous ovarian cancer? A single institution experience. International Journal of Surgery, 41, 1-5. doi: http://doi.org/10.1016/j.ijsu.2017.03.023 
[18] Mengardo, V., Bencivenga, M., Weindelmayer, J., Pavarana, M., Giacopuzzi, S., de Manzoni, G. (2018). Para-aortic lymphadenectomy in surgery for gastric cancer: current indications and future perspectives. Updates in Surgery, 70 (2), $207-211$. doi: http://doi.org/10.1007/s13304-018-0549-x

[19] Roze, J. F., Hoogendam, J. P., van de Wetering, F. T., Spijker, R., Verleye, L., Vlayen, J. et. al. (2018). Positron emission tomography (PET) and magnetic resonance imaging (MRI) for assessing tumour resectability in advanced epithelial ovarian/ fallopian tube/primary peritoneal cancer. Cochrane Database of Systematic Reviews. doi: http://doi.org/10.1002/14651858. cd012567.pub2

[20] Ong, M. L. H., Schofield, J. B. (2016). Assessment of lymph node involvement in colorectal cancer. World Journal of Gastrointestinal Surgery, 8 (3), 179-192. doi: http://doi.org/10.4240/wjgs.v8.i3.179

\title{
SWOT-ANALYSIS OF MODELS OF ORGANIZATION OF PROVISION OF PRIMARY HEALTH CARE IN THE UNITED TERRITORIAL COMMUNITIES
}

\author{
Grigorii Ursol \\ Department of thoracic and abdominal surgery \\ High Level Certificate thoracic surgeon ${ }^{2}$ \\ Alexandr Skrypnyk \\ Deputy Director of Healthcare department \\ Kirovograd Region State Administration \\ 74 Chmilenko str., Kropyvnytskyi, Ukraine, 25022 \\ uozkir3@ukr.net \\ Olha Vasylenko \\ Department organizational and personnel work ${ }^{2}$ \\ Department of social medicine, regulation and business in Healthcare academic \\ olgeca@i.ua
}

${ }^{1}$ Kharkiv Medicine Academy of postgraduate education of Ukraine's Healthcare Ministry

58 Amosova str., Kharkiv, Ukraine, 61176

${ }^{2}$ Medical centre PE "Hospital of St. Luke"

65 Velyka Perspektivna str., Kropyvnytskyi, Ukraine, 25006

\footnotetext{
Abstract

The article analyzes the strengths, weaknesses, potential opportunities and threats in the process of forming and making appropriate management decisions to integrate health facilities into united territorial communities (UTC) infrastructure, or other options, in the process of decentralization. The basic package of new legislative and regulatory documents has been worked out, which envisages radical changes and systemic reforms, decentralization of power - transfer from the executive bodies to local self-government bodies of a considerable part of powers, resources and responsibilities. A number of reform changes have been identified, which may lead to the expected institutional, organizational and structural-functional changes of the existing public health management system in Ukraine and changes in the individual functional characteristics of the entities of this system. The differences between medical reforms in terms of administrative reform, the role of UTC in this process, in relation to a number of other European countries are considered. On this basis, possible options for the development of events in the context of territorial governance of these processes in the system of health in Ukraine have been proposed. In order to continue scientific research in this direction, the next stage of the evolution of the formation
} 